\title{
Analysis and relationship between the anthropometric and somatotype characteristics and cardiovascular capacity in amateur mountain runners: a pilot study
}

\author{
Mikel Zubieta', Ibai Garcia-Tabar², Daniel Castillo³, Javier Raya-González³, Aitor Iturricastillo², Irati Aritzeta', \\ Kristian Alvarez', Javier Yanci² \\ ${ }^{1}$ Facultad de Educación y Deporte. Universidad del País Vasco, UPV/EHU. Vitoria-Gasteiz. ${ }^{2}$ Society, Sports and Physical Exercise Research Group (GIKAFIT). Departamento de Edu- \\ cación Física y Deportiva, Facultad de Educación y Deporte, Universidad del País Vasco, UPV/EHU. Vitoria-Gasteiz. ${ }^{3}$ Facultad de Ciencias de la Salud, Universidad Isabel I. Burgos.
}

doi: $10.18176 /$ archmeddeporte.00057

Received: 08/10/2020 Accepted: 04/06/2021

Key words:

Body composition Oxygen consumption

Physiological thresholds. Trail running. Kinanthropometry.

\section{Summary}

Purpose: The aim of this study was to describe the anthropometrical and cardiovascular characteristics of short course trail runners and analyze the associations, if any, between both anthropometric and cardiovascular features of amateur trail runners. Material and method: Anthropometrical evaluation and an incremental maximum test with $10 \%$ of grade on a treadmill were performed on a group of 10 short distance amateur trail runners.

Results: Significant negative correlations were found between the body max index (BMI) and the speed at VT1 (Vel ${ }_{\mathrm{VT}}$ ) $(r=-0,95, p<0,001)$, or the time to reach VT1 $(r=-0,91, p=0,002)$ and between the body fat percentage and the respiratory exchange ratio at VT2 $(r=-0,80, p=0,016)$ or the time to reach VT2 $(r=-0,83, p=0,01)$. Calf circumference was also found to be positively associated with oxygen consumption at VT1 $(r=0,74, p=0,037)$, at VT2 $(r=0,90, p=0,002)$ and with the maximal oxygen uptake $(r=0,85, p=0,007)$.

Conclusions: Results indicate that both body fat percentage and calf circumference could be related to the performance on an incremental test protocol with inclination in amateur trail runners.

Análisis y asociación entre las características antropométricas, somatotipo y capacidad cardiovascular en corredores de montaña de categoría amateur: un estudio piloto

\section{Resumen}

Objetivo: Los objetivos del presente estudio fueron describir las características antropométricas y la capacidad cardiovascular de corredores amateurs de trail running de corta distancia y analizar si existe asociación entre las características antropométricas y la capacidad cardiovascular en los corredores de montaña.

Material y método: A un grupo de 10 corredores de trail running de corta distancia de categoría amateur se les realizó un análisis antropométrico y un test incremental máximo con un 10\% de inclinación en tapiz rodante.

Resultados: Se encontraron correlaciones significativas y negativas entre el índice de masa corporal (IMC) y la velocidad alcanzada al primer umbral ventilatorio $\left(V_{\text {Vel }}\right)(r=-0,95, p<0,001)$, así como con el tiempo en alcanzar el VT1 $\left(t_{V T 1}\right)(r=-0,91$, $p=0,002)$ y entre porcentaje (\%) de grasa corporal y el índice de intercambio respiratorio al segundo umbral ventilatorio $\left(R E R_{V T 2}\right)(r=-0,80, p=0,016)$ así como con el tiempo en alcanzar el VT2 $\left(t_{V T 2}\right)(r=-0,83, p<0,01)$. También se encontraron correlaciones significativas y positivas entre el perímetro de pierna y el consumo de oxígeno al VT1 $\left(\mathrm{VO}_{2 V T 1}\right)(r=0,74, p=0,037)$, el consumo de oxígeno al VT2 $\left(V_{2 V T 2}\right)(r=0,90, p=0,002)$ y el consumo máximo de oxígeno $\left(V_{2}{ }_{\text {max }}{ }^{2}\right)(r=0,85, p=0,007)$. Conclusiones: Los resultados obtenidos en el presente estudio ponen de manifiesto que tanto el $\%$ de grasa corporal como el perímetro de la pierna pueden estar asociados al rendimiento en una prueba incremental con inclinación en los corredores amateur de montaña participantes en el estudio. 


\section{Introduction}

Trail running (mountain running) is a sports discipline that involves races along mountain tracks of varying distances ranging from $1 \mathrm{~km}$ to more than $100 \mathrm{~km}$, in which important elevation gains and losses need to be overcome through different types of terrain and in variable weather conditions ${ }^{1}$. Due to the characteristics of the races, this type of sport places high demands on participants at both a neuromuscu$\operatorname{lar}^{2}$ and cardiovascular ${ }^{3}$ level. Therefore, trail running races are highly demanding from a physiological point of view. Possibly due to this high demand and the athletic challenge involved, the practice of trail running has become increasingly popular over the last few years, with regard to the number of races, competitions and participants, primarily at an amateur level ${ }^{4-6}$. This considerable boom has led mountain running to be recently recognised by the World Athletics and to have its own world championship ${ }^{7}$. However, despite this boom, in practice the existing scientific literature relating to this sport is still limited and even more so for runners at an amateur level. Consequently, there is a need for more scientific studies to analyse this sports discipline and the characteristics of its participants.

Although with regard to other endurance disciplines, it has been reported that body composition is a determining factor in athletic performance ${ }^{3,9-12}$, due to the characteristics of trail running, in which athletes must overcome important elevation gains, the anthropometric characteristics of the runners could take on even greater importance in order to achieve sporting success 3 . Prior investigations have studied the body composition of mountain runners, analysing the anthropometric characteristics of long-distance runners (42 km - more than $217 \mathrm{~km}$ ) 9,14. However, given that studies made on the anthropometric characteristics of short-distance runners $(<42 \mathrm{~km})$ are limited ${ }^{15,16}$, it could be of interest to conduct further studies in this regard, in order to obtain scientific evidence on the anthropometric profile of short-distance mountain runners.

On the other hand, as in other endurance disciplines ${ }^{17-20}$, an analysis has also been made of the physical performance and physiological characteristics of the runners taking part in trail running $3,6,8,15,16,21-24$. It is common to use laboratory tests to measure the cardiovascular capacity of runners 3,8,15,16 analysing maximal and submaximal aerobic performance markers that make it possible to determine the physiological characteristics of the athletes and to subsequently prescribe, monitor and assess training. Most of the in-laboratory protocols used with mountain runners have been conducted with no incline ${ }^{26-28}$. However, given the fact that a considerable part of the trail running races takes place on uphill terrain and that it has been reported that the running economy or the energy cost of the runners could be different depending on whether they are running on level terrain or uphill ${ }^{21}$, further studies are needed in order to analyse the physiological characteristics of trail runners using protocols with an incline $e^{3,29-31}$.

Prior studies conducted with endurance athletes analysed the relationship between body composition and physiological performance in a laboratory test ${ }^{11,32-35}$. However, for trail runners, the knowledge available on the influence of the anthropometric characteristics of the runners on physiological performance in a standardised laboratory test is very limited. Despite the fact that some studies have reported that the anthropometric characteristics of mountain runners have a significant correlation with performance in competition9,16,37, we have found no studies that analyse the relationship between body composition and performance in laboratory-based incremental running tests. Knowledge of whether or not anthropometric characteristics are related to the physiological characteristics of the trail runners could be relevant to understanding the extent to which the results obtained in an incremental test, which are generally used to monitor the adaptations induced by the training process, could in some way be influenced by changes in body composition.

Considering the importance of evaluating the anthropometric characteristics and cardiovascular capacity of mountain runners using protocols with an incline, with a view to designing personalised training programs, the objectives of this study were to firstly describe the anthropometric characteristics, somatotype and cardiovascular capacity of short-distance $(<42 \mathrm{~km})$ trail runners and, secondly, to analyse whether there is any relationship between the anthropometric characteristics and the cardiovascular capacity of mountain runners at an amateur level.

\section{Material and method}

\section{Participants}

10 mountain runners took part in this study, who were competing in short-distance races at an amateur level (38.0 \pm 9.5 years, $174.0 \pm 8.1$ $\left.\mathrm{cm}, 65.21 \pm 9.52 \mathrm{~kg}, 8.58 \pm 2.28 \% \mathrm{fat}, 21.44 \pm 1.96 \mathrm{~kg} \cdot \mathrm{m}^{-2}\right)$ with a valid federation membership, of which there were 9 men and 1 woman. In order to take part in the study, participants were required to have at least one year of experience in mountain races, at least 5 years of experience in an endurance sport as a member of a federation, and not to have suffered an injury in the 5 months prior to the study. Before the study started, all participants were informed of the objectives and methodology to be used during the investigation and they had the possibility to freely withdraw and with no penalty at any stage of the investigation. Before taking part in the study, they signed an informed consent form. The investigation followed the guidelines established by the Declaration of Helsinki (2013) and was approved by the Ethics Committee for Research on Human Subjects (CEISH) of the University of the Basque Country (UPV/EHU) (Ceid Ref. No. : M10/2017/200).

\section{Procedure}

During the competition season, and always one month before an important race, the participants were evaluated in a single session, in which an analysis was made of their anthropometric profile as well as a laboratory-based maximal incremental running test performed on a treadmill. The runners were familiar with tests of this nature, having 
performed them previously as part of their training program. They were asked not to alter their daily routine with regard to diet and training in the days prior to the investigation in order to maintain their normal condition. For the tests, the participants were asked to come well-rested and hydrated, to have performed low-intensity exercise ( $<90 \mathrm{~min}$ at $<70 \%$ of the maximum individual heart rate, $\mathrm{FC}_{\max }$ ) during the days prior to the test, to have spent at least 4 days resting since the last competition (to ensure glycogen replenishment) and not to eat anything in the $2 \mathrm{~h}$ prior to the tests. Of the 10 mountain runners taking part, the results of 2 runners in the laboratory-based incremental test were not included in the analysis. This was either due to problems with the measurement of the study variables or to logistics problems when conducting the test.

\section{Measurements}

Anthropometric and somatotype characteristics The measurements of the anthropometric characteristics were taken following the guidelines established by the International Society Advancement Kinanthropometry (ISAK) ${ }^{38}$. A scale with measuring rod (Seca, Bonn, Germany) was used to measure the height and body mass with an accuracy of $1 \mathrm{~mm}$ and $0.05 \mathrm{~kg}$ respectively. The height and body mass measurements were then used to calculate the Body Mass Index (BMI). The skin folds (biceps, triceps, subscapular, abdomen, iliac crest, supraspinale, anterior thigh and medial calf) were measured using a skinfold calliper (Holtain, Crymych, United Kingdom) and the sum of the 8 folds was calculated ( $\Sigma$ folds). The percentage of body fat was calculated using the Yuhasz formula ${ }^{39}$. The circumferences [(relaxed arm, flexed and contracted arm, waist (minimum)], hip (maximum) were measured using a non-flexible tape measure graduated in millimetres (Holtain 110P-98606, Crymych, United Kingdom). The circumferences were used to calculate the ratio between the waist circumference and the hip circumference (waist-hip index). Furthermore, a sliding calliper (HLT-100, Holtain Ltd., Crymych, United Kingdom) was used to measure the biepicondylar (humerus) and bicondylar (femur) widths. Finally, a calculation was made of the somatotype component ${ }^{40}$ of each mountain runner taking part.

Laboratory-Based Maximal Incremental Running Testing: The participants performed a continuous Maximal Incremental Running Test on a treadmill (ERGelek ${ }^{\text {TM }}$ EG2, Vitoria-Gasteiz, Spain) using the protocol with incline described above for mountain runners ${ }^{31}$. The test started at $6 \mathrm{~km} \cdot \mathrm{h}^{-1}$, always with an incline of 10\%. Every $2.5 \mathrm{~min}$, the speed was increased by $1 \mathrm{~km} \cdot \mathrm{h}^{-1}$. The aforementioned treadmill, which had been calibrated by the manufacturer prior to the start of the study, was used to continuously record the running speed and the test time. At the end of each stage and on completion of the test, the heart rate (HR) was measured with a heart rate monitor (Polar ${ }^{\mathrm{TM}}$ Electro Oy, Kempele, Finland). The following ventilatory variables were analysed: ventilation (VE), oxygen uptake $\left(\mathrm{VO}_{2}\right)$ and carbon dioxide production $\left(\mathrm{VCO}_{2}\right)$, which were recorded throughout the entire test using a gas analyser (Medisoft $^{\text {TM }}$ Ergocard, Medisoft Group, Sorinnes, Belgium). Furthermore, the Respiratory Exchange Rate (RER) was calculated as the ratio between
$\mathrm{VCO}_{2} \cdot \mathrm{VO}_{2}-141,42$. Apart from the $\mathrm{HR}$; the variables were obtained at the ventilatory threshold 1 (VT1), which was considered to be the moment at which the ventilation-volume of oxygen ratio $\left(\mathrm{VE} \cdot \mathrm{VO}_{2}-1\right)$ and the end-tidal oxygen tension (PETO2) started to increase without the corresponding increase in the end-tidal carbon dioxide tension (PET$\mathrm{CO} 2)^{44,45}$ and at ventilatory threshold 2 (VT2), which is considered as the moment when the values of both equivalents $\left(\mathrm{VCO}_{2} \cdot \mathrm{VE}-1\right.$ and $\left.\mathrm{VO}, \mathrm{VE}-1\right)$ increased with a drop in PETCO2 ${ }^{46}$, and the maximum values (Max). The test was considered to be maximum when two of the following three criteria were met: a) the $\mathrm{VO}_{2}$ ceased to increase despite the increase in the speed demanded, b) $90 \%$ of the heart rate was exceeded $\left(H R_{\max }\right)$ estimated according to age (220-age), c) the RER was greater than 1.15

\section{Statistical analysis}

The results are shown as a mean \pm standard deviation of the mean. In order to determine the magnitudes of the relationships between the anthropometric variables and the variables obtained in the laboratorybased incremental running test, the Pearson ( $r$ ) correlation was used with confidence intervals $(\mathrm{Cl})$ at $95 \%$. The interpretation of the correlations was made through the following magnitude scale: trivial $(r<0.1)$, low $(r=0.10-0.30)$, moderate $(r=0.31-0.50)$, high $(r=0.51-0.70)$, very high $(r=0.71-0.90)$ and almost perfect $(r>0.9)^{47}$. The statistical analysis was made with the Statistical Package for Social Sciences (SPSSTM Inc, version 23.0 for Windows, Chicago, IL, EE.UU.). The statistical significance cut-off was set at $p<0.05$.

\section{Table 1. Results of the anthropometric and somatotype charac-} teristics of mountain runners $(n=10)$.

\begin{tabular}{|c|c|c|c|}
\hline & Minimum & Maximum & Mean \pm SD \\
\hline \multicolumn{4}{|l|}{ Skin folds } \\
\hline Triceps (mm) & 4.30 & 16.70 & $8.58 \pm 3.76$ \\
\hline Subscapular (mm) & 5.80 & 12.20 & $8.20 \pm 1.95$ \\
\hline Biceps (mm) & 2.40 & 5.70 & $3.48 \pm 1.20$ \\
\hline Iliac crest (mm) & 5.90 & 15.00 & $9.12 \pm 3.30$ \\
\hline Supraspinale (mm) & 3.80 & 12.50 & $6.44 \pm 2.59$ \\
\hline Abdomen (mm) & 4.50 & 21.50 & $11.30 \pm 5.72$ \\
\hline Thigh (mm) & 3.70 & 23.60 & $10.78 \pm 5.50$ \\
\hline Calf $(\mathrm{mm})$ & 3.40 & 10.00 & $5.74 \pm 2.22$ \\
\hline$\Sigma$ of 8 folds $(\mathrm{mm})$ & 38.30 & 109.60 & $62.65 \pm 21.89$ \\
\hline Body fat $(\%)$ & 5.70 & 12.60 & $8.58 \pm 2.28$ \\
\hline \multicolumn{4}{|l|}{ Circumferences } \\
\hline Relaxed arm (cm) & 22.80 & 30.50 & $27.43 \pm 2.43$ \\
\hline Contracted and flexed arm $(\mathrm{cm})$ & 25.50 & 33.10 & $29.83 \pm 2.55$ \\
\hline Waist $(\mathrm{cm})$ & 66.70 & 84.00 & $74.44 \pm 4.93$ \\
\hline $\mathrm{Hip}(\mathrm{cm})$ & 86.00 & 99.70 & $92.82 \pm 4.10$ \\
\hline $\operatorname{Leg}(\mathrm{cm})$ & 32.30 & 40.50 & $36.60 \pm 2.50$ \\
\hline Waist-Hip index & 0.76 & 0.85 & $0.80 \pm 0.04$ \\
\hline \multicolumn{4}{|l|}{ Widths } \\
\hline Humerus (cm) & 5.50 & 37.90 & $9.83 \pm 9.88$ \\
\hline Femur $(\mathrm{cm})$ & 8.00 & 11.20 & $9.75 \pm 0.93$ \\
\hline \multicolumn{4}{|l|}{ Somatotype } \\
\hline Endomorph & 1.40 & 3.30 & $2.20 \pm 0.76$ \\
\hline Mesomorph & 2.80 & 5.90 & $4.62 \pm 1.16$ \\
\hline Ectomorph & 1.80 & 4.50 & $3.16 \pm 0.87$ \\
\hline
\end{tabular}

ST = standard deviation; $\Sigma=$ sum 
Table 2. Results obtained in the laboratory-based maximum incremental test by the mountain runners $(n=8)$.

\begin{tabular}{|c|c|c|c|}
\hline & Minimum & Maximum & Mean \pm SD \\
\hline \multicolumn{4}{|l|}{ VT1 } \\
\hline $\mathrm{VE}_{\mathrm{VT} 1}\left(\mathrm{~L} \cdot \mathrm{min}^{-1}\right)$ & 60.52 & 83.54 & $71.36 \pm 8.63$ \\
\hline $\mathrm{VO}_{2 \mathrm{VT} 1}\left(\mathrm{~L} \cdot \mathrm{min}^{-1}\right)$ & 2.32 & 3.22 & $2.86 \pm 0.27$ \\
\hline $\mathrm{VO}_{2 \mathrm{VT1}}\left(\mathrm{mL} \cdot \mathrm{kg}^{-1} \cdot \mathrm{min}^{-1}\right)$ & 38.57 & 51.62 & $43.98 \pm 4.33$ \\
\hline $\mathrm{VCO}_{2 \mathrm{VT} 1}\left(\mathrm{~L} \cdot \mathrm{min}^{-1}\right)$ & 2.16 & 2.94 & $2.67 \pm 0.23$ \\
\hline $\mathrm{RER}_{\mathrm{VT} 1}$ & 0.89 & 0.96 & $0.93 \pm 0.02$ \\
\hline $\operatorname{Vel}_{V T} 1\left(\mathrm{~km} \cdot \mathrm{h}^{-1}\right)$ & 7.00 & 8.00 & $7.44 \pm 0.53$ \\
\hline $\mathrm{t}_{\mathrm{VT} 1}(\min : \mathrm{s})$ & $3: 15$ & $6: 45$ & $5: 10 \pm 1: 19$ \\
\hline \multicolumn{4}{|l|}{$V T 2$} \\
\hline $\mathrm{VE}_{\mathrm{VT2}}\left(\mathrm{L} \cdot \mathrm{min}^{-1}\right)$ & 103.37 & 165.18 & $134.02 \pm 17.65$ \\
\hline $\mathrm{VO}_{2 \mathrm{VT2}}\left(\mathrm{L} \cdot \mathrm{min}^{-1}\right)$ & 3.35 & 5.14 & $4.10 \pm 0.55$ \\
\hline $\mathrm{VO}_{2 \mathrm{VT2}}\left(\mathrm{mL} \cdot \mathrm{kg}^{-1} \cdot \mathrm{min}^{-1}\right)$ & 55.93 & 71.32 & $63.02 \pm 4.65$ \\
\hline $\mathrm{VCO}_{2 \mathrm{VT2}}\left(\mathrm{L} \cdot \mathrm{min}^{-1}\right)$ & 3.49 & 5.77 & $4.48 \pm 0.65$ \\
\hline $\mathrm{RER}_{\mathrm{VT2}}$ & 1.04 & 1.23 & $1.09 \pm 0.06$ \\
\hline $\mathrm{Vel}_{\mathrm{VT2}}\left(\mathrm{km} \cdot \mathrm{h}^{-1}\right)$ & 10.00 & 13.00 & $11.56 \pm 0.88$ \\
\hline $\mathrm{t}_{\mathrm{VT2}}(\mathrm{min}: \mathrm{s})$ & $10: 45$ & $18: 15$ & $15: 03 \pm 2: 13$ \\
\hline \multicolumn{4}{|l|}{ Max } \\
\hline $\mathrm{VE}_{\max }\left(\mathrm{L} \cdot \mathrm{min}^{-1}\right)$ & 114.15 & 180.81 & $147.53 \pm 23.14$ \\
\hline $\mathrm{VO}_{2 \max }^{\max }\left(\mathrm{L} \cdot \mathrm{min}^{-1}\right)$ & 3.42 & 5.59 & $4.23 \pm 0.70$ \\
\hline $\mathrm{VO}_{2 \max }\left(\mathrm{mL} \cdot \mathrm{kg}^{-1} \cdot \mathrm{min}^{-1}\right)$ & 56.48 & 77.50 & $64.66 \pm 6.41$ \\
\hline $\mathrm{VCO}_{2 \max }\left(\mathrm{L} \cdot \mathrm{min}^{-1}\right)$ & 3.77 & 6.09 & $4.73 \pm 0.70$ \\
\hline $\mathrm{RER}_{\max }$ & 1.09 & 1.24 & $1.12 \pm 0.05$ \\
\hline $\mathrm{Vel}_{\max }^{\max }\left(\mathrm{km} \cdot \mathrm{h}^{-1}\right)$ & 11.00 & 13.00 & $12.33 \pm 0.71$ \\
\hline $\mathrm{t}_{\text {agot }}$ (min:s) & $12: 38$ & $18: 58$ & $16: 42 \pm 1: 58$ \\
\hline $\mathrm{HR}_{\max }\left(p \cdot \min ^{-1}\right)$ & 160 & 202 & $184.90 \pm 11.73$ \\
\hline
\end{tabular}

$\mathrm{SD}=$ Standard deviation, $\mathrm{VT} 1=$ first ventilation threshold, $\mathrm{VT} 2=$ second ventilation threshold $\mathrm{Max}=$ max values, $\mathrm{VE}=$ lung ventilation, $\mathrm{VO}_{2}=$ oxygen consumption (absolute and relativized to body mass, $\mathrm{VCO}_{2}=$ carbon dioxide production, $\mathrm{RER}=$ respiration exchange rate, $\mathrm{Vel}=$ velocity, $\mathrm{t}=$ time, tagot $=$ time to exhaustion, HRmax = maximum heart rate.

\section{Results}

Table 1 shows the results of the anthropometric characteristics (skin folds, circumferences, widths and estimated variables) and of the somatotype of the mountain runners taking part in the study.

Table 2 gives the results obtained by the mountain runners taking part in this study in the laboratory-based maximal incremental running test, for the values obtained at VT1, VT2 and also the maximum values.

With regard to the relationship between the anthropometric characteristics and the results obtained in the laboratory-based incremental test, significant negative correlations were found between the BMI and $\mathrm{VeI}_{V T 1}\left(r=-0.95, p<0.001\right.$, almost perfect) (Figure 1A), the BMI and $t_{V T 1}$ $(r=-0.91, p=0.002$, almost perfect), between the percentage of body fat and the RER ${ }_{\text {VT2 }}(r=-0.80, p=0.016$, very high $)$ and between $\%$ of fat and $t_{v T 2}(r=-0,83, p=0,01$, very high) (Figure 1B). Significant positive correlations were also found between the circumference of the calf and $\mathrm{VO}_{2 \mathrm{VT1}}(r=0.74, \mathrm{p}=0.037$, very high $)$, the $\mathrm{VO}_{2 \mathrm{VT2}}(r=0.90, \mathrm{p}=$ 0.002 , almost perfect) (Figure $2 \mathrm{~A}$ ) and $\mathrm{VO}_{2 \max }(r=0.85, \mathrm{p}=0.007$, very high) (Figure 2B).
Figure 1. Correlation between the body mass index (BMI) and the velocity achieved at the first ventilation threshold $\left(\mathrm{Vel}_{\mathrm{VT1}}\right)(1 \mathrm{~A})$ and between the percentage (\%) of fat and the time employed to reach the second ventilatory threshold $\left(t_{\mathrm{vT2}}\right)(1 \mathrm{~B})$. Solid black lines = linear regression lines. Dashed black lines = confidence intervals of $95 \%$.

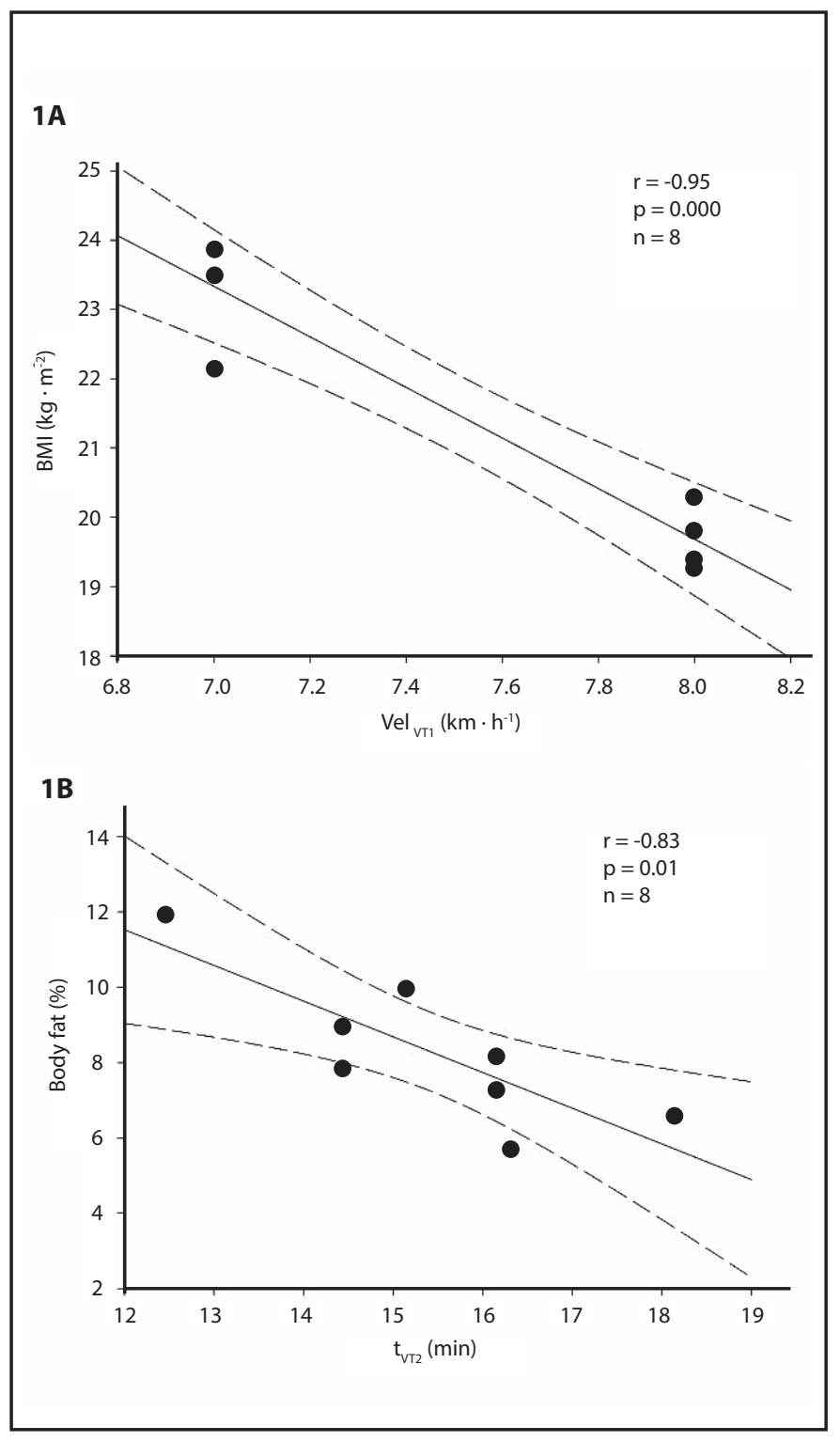

\section{Discussion}

The study objectives were, on the one hand, to describe the anthropometric characteristics and the performance in a standard laboratory-based maximal incremental running test of mountain runners at an amateur level and, on the other hand, to analyse the relationship between the anthropometric characteristics of these runners and their cardiovascular performance. Based on the scientific literature consulted, this study is the first to analyse the relationship between the anthropo- 
Figure 2. Correlation between the calf circumference and oxygen consumption at the second ventilatory threshold $\left(\mathrm{VO}_{2 \mathrm{VT2}}\right)(2 \mathrm{~A})$ and maximal oxygen consumption $\left.\mathrm{VO}_{2 \max }\right)(2 \mathrm{~B})$. Solid black lines = linear regression lines. Dashed black lines $=$ confidence intervals of $95 \%$.

$2 A$

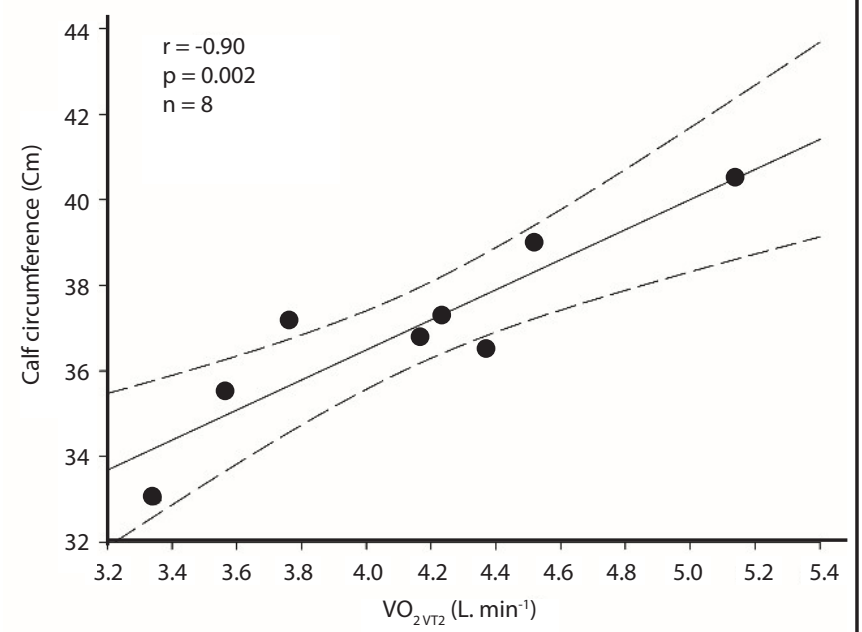

2B

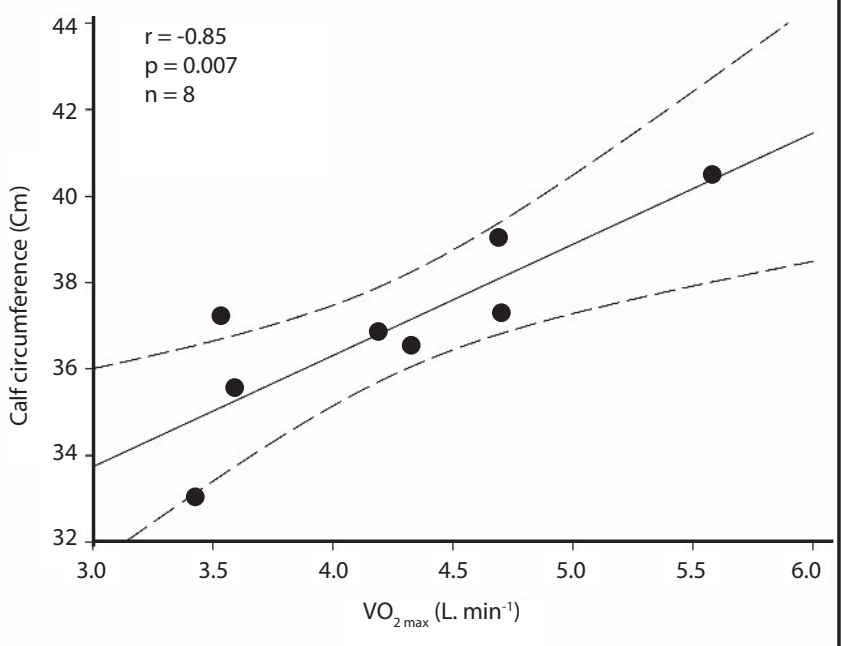

metric characteristics and the performance obtained in a laboratory test with an incline, for trail runners in an amateur category who regularly compete in short-distance mountain races ( $<42 \mathrm{~km}$ ). considering the increasing popularity of amateur trail running over the last few years, an in-depth knowledge of this relationship could be extremely helpful for sports coaches and for the athletes themselves, in order to optimise the training process.

The anthropometric characteristics of endurance runners has been extensively discussed in scientific literature ${ }^{29,48-50}$, possibly due to the close relationship with athletic performance ${ }^{11,36,50,51}$. Specifically, the anthropometric characteristics of trail runners have also been analysed $9,12,14,16,48,52$, given that this could be particularly relevant to athletic performance in this discipline due to the fact that body mass may have a significant influence when running on terrain with elevation gains and losses $^{16}$. The runners taking part in this study had a body fat percentage of $8.58 \pm 2.28 \%$ and a BMl of $21.44 \pm 1.86 \mathrm{~kg} \cdot \mathrm{m}^{-2}$. These results are similar to those obtained in the previous study made with short-distance trail runners $\left(<42 \mathrm{~km}\right.$ ) by Alvero-Cruz et al. ${ }^{16}$ (\% body fat $=9.96 \pm 1.35 \%$, $\left.\mathrm{BMI}=22.67 \pm 1.62 \mathrm{~kg} \cdot \mathrm{m}^{-2}\right)$. However, both the $\%$ of body fat and the $\mathrm{BMI}$ of the runners taking part in this study and in that of Alvero-Cruz et al. ${ }^{16}$ were less (45.9\% for $\%$ of fat and $10.78 \%$ for BMI) than the values obtained for long-distance runners (> $42 \mathrm{~km}$ ), for runners taking part in a161 $\mathrm{km}$ race $\left(\% \mathrm{fat}=16.1 \pm 4.1 \%, \mathrm{BMl}=24.8 \pm 2.7 \mathrm{~kg} \cdot \mathrm{m}^{-2}\right)^{12}$, and also for those taking part in a $217 \mathrm{~km}$ race $(\% \mathrm{fat}=13.2 \pm 1.8 \%, \mathrm{BMI}=24.8 \pm 2.7$ $\left.\mathrm{kg} \cdot \mathrm{m}^{-2}\right)^{9}$ as well as participants in 24-hour races (\% fat $=16.1 \pm 4.1 \%$, BM $\left.=23.1 \pm 1.8 \mathrm{~kg} \cdot \mathrm{m}^{-2}\right)^{52}$. Contrary to what might be expected, long-distance runners had a higher \% of body fat and a higher BMI than short-distance runners. A priori, it would be expected that long-distance runners would have lower fat percentages and BMI due to the fact that, in principle, the training performed to prepare for races of this type and the actual competitions ought to be longer and, consequently, with a greater use of energy substrates through lipid uptake ${ }^{53}$, which would lead to a sharper drop in the \% of fat and BMI in comparison to short-distance runners. It is possible that these contradictory results are due to the characteristics of the sample. Although amateurs, the runners taking part in this study were at a high competition level, while those runners taking part in the studies by Hoffman et al. ${ }^{12}$ and Belli et al. ${ }^{9}$ were from extremely varied levels and included athletes who completed the race and those who did not. Another plausible explanation to account for the marked differences between the studies could be related to the different methodology used to estimate the body fat percentage. All the same, both Hoffman et al. ${ }^{12}$ and Belli et al. ${ }^{9}$ found a positive relationship between the body fat percentage and race time. Therefore, in future investigations, it could be of interest to compare the fat \% and the BMI of short- and long-distance runners of a similar competition level. Taking account of the fact that for both short-distance races ${ }^{3,16}$ and long-distance ones $s^{9,12}$ a positive relationship was observed between the $\%$ of body fat and the competition time, it seems reasonable to think that one of the de trail runners' objectives should be to reduce the body fat \% and BMI in order to improve their competition performance. Nevertheless, the possible relationship between the fat $\%$ and competition performance may also be related to the fact that, in order to improve performance, more adequate training is required and, therefore, the actual training may lead to a change in the body fat \%. However, bearing in mind that Hoffman ${ }^{37}$ reported that in very long-distance races $(161 \mathrm{~km})$ a higher percentage of body fat measured prior to the race may not be a disadvantage in races with a high energy demand ${ }^{37}$, considering that this type of competition may require high lipid demands. In this respect, further studies may be necessary for the different types of trail running. 
Despite the fact that numerous studies have used laboratory tests to analyse the physiological characteristics of trail runners and have reported data for the maximal values obtained ${ }^{3,7,54}$, few studies have focussed on analysing the submaximal values ${ }^{16,22,25}$. The analysis of these values may help to better understand the characteristics of mountain runners and make it possible to better plan training sessions. Furthermore, taking account of the fact that a large part of the mountain running competitions involve significant elevation gains, the analysis of the physiological characteristics of the runners using protocols with an incline could be relevant $23,25,55$. In this regard, the athletes taking part in our study achieved a relative $\mathrm{VO}_{2 \max }$ of $64.66 \pm 6.41 \mathrm{~mL} \cdot \mathrm{kg}^{-1} \cdot \mathrm{min}^{-1}$. These results are similar to the $\mathrm{VO}_{2 \max }$ figures for high-level short-distance runners $(27 \mathrm{~km})\left(61.1-69.7 \mathrm{~mL} \cdot \mathrm{kg}^{-1} \cdot \mathrm{min}^{-1}\right)^{15}$ obtained by Alvero-Cruz et al..$^{16}$ with trained runners $\left(67 \pm 7 \mathrm{~mL} \cdot \mathrm{kg}^{-1} \cdot \mathrm{min}^{-1}\right)$ and even to those obtained by Björklund et al. ${ }^{3}$, for elite runners $\left(68.1 \pm 5.8 \mathrm{~mL} \cdot \mathrm{kg}^{-1} \cdot \mathrm{min}^{-1}\right.$ in men). Likewise, the results obtained by Alvero-Cruz et al. ${ }^{16}$ for $\mathrm{VO}_{2}$ at VT1 $\left(43 \pm 6 \mathrm{~mL} \cdot \mathrm{kg}^{-1} \cdot \mathrm{min}^{-1}\right)$ are very similar to those obtained in this study $\left(43.98 \pm 4.33 \mathrm{~mL} \cdot \mathrm{kg}^{-1} \cdot \mathrm{min}^{-1}\right)$, although slightly lower (7.97\%) than those observed in $\mathrm{VO}_{2 \text { VT2 }}\left(58 \pm 5 \mathrm{~mL} \cdot \mathrm{kg}^{-1} \cdot \mathrm{min}^{-1} \mathrm{vs} 63.02 \pm 4.65 \mathrm{~mL} \cdot \mathrm{kg}^{-1} \cdot \mathrm{min}^{-1}\right)$. Due to the fact that the studies analysed use different measurement protocols, different sampling characteristics with regard to age and sex and different competition levels, it is difficult to determine the influence of these variables on $\mathrm{VO}_{2}$ performance. However, the results obtained herein with regard to $\mathrm{VO}_{2 \max }$. are higher (13.04\%) than those obtained by Wüthrich et al..$^{31}\left(57.2 \pm 6.1 \mathrm{~mL} \cdot \mathrm{kg}^{-1} \cdot \mathrm{min}^{-1}\right)$ for participants who were able to complete an ultra-distance race $(110 \mathrm{Km})$, using the same protocol and also higher (12.65\%) than the results obtained by Fornasiero et al. ${ }^{22}$ for ultra-distance amateur runners $(65 \mathrm{~km})$ with a protocol with an incline. These results could suggest that a high $\mathrm{VO}_{2 \max }$ has no determinant influence on very long distance races. As previously described, for a $65 \mathrm{~km}$ race, VT1 is not exceeded during approximately $82 \%$ of the competition time and the average intensity of the race is approximately $77 \%$ of $\mathrm{HR}_{\max }$ (approximately $66 \%$ of $\mathrm{VO}_{2 \max }$. . $^{22}$. By contrast, for shortdistance races $(27 \mathrm{~km})$ the average running intensity was reported to be approximately $89 \%$ of $\mathrm{HR}_{\max }{ }^{15}$. As a result of these different race characteristics, the training of the runners may seek different goals and, therefore, different physiological adaptations.

A number of prior studies conducted with asphalt runners analysed the relationship between the anthropometric characteristics and the laboratory test results $11,29,34,36$. However, there is no evidence for trail runners in this regard. The results obtained in this study show that, despite the fact that no significant relationship was obtained between the anthropometric characteristics of the runners and the maximum values for $\mathrm{VO}_{2^{\prime}}$ significant negative correlations were observed between the $\mathrm{BMI}$ and $\mathrm{Vel}_{\mathrm{VT} 1}$, the $\mathrm{BMI}$ and $\mathrm{t}_{\mathrm{VT} 1}$, between the body fat $\%$ and $\mathrm{RER}_{\mathrm{VT2}}$ and between the fat $\%$ and $t_{V T 2}$. These results indicate that the runners with a greater fat $\%$ or BMI had a poorer submaximal performance for the test with a ramp. Despite the fact that there are no similar studies for trail runners in order to compare these results, these relationships appear to indicate that the \% of fat and BMI can play a very important role when running on a ramp. These results reveal that the BMI and fat $\%$ could have a better relationship with the submaximal values obtained in the laboratory test in comparison to the maximal values.

On the other hand, the results obtained in this study show significant positive correlations between the calf circumference and $\mathrm{VO}_{2 \mathrm{VT} 1^{\prime}}$ $\mathrm{VO}_{2 \mathrm{VT2}}$ and $\mathrm{VO}_{2 \max }$. Although a number of studies conducted with asphalt runners reported greater mass in the lower limbs (generally measuring the calf circumference) is related to poorer running economy ${ }^{56-58}$, leading to poorer performance on level or slightly sloping terrain, the results obtained herein show that this trend may be the opposite for races on sloping terrain. Vernillo et al. ${ }^{24}$ reported that the power required for uphill terrain is greater than for level running given that, with the increase in the elevation profile, runners tend to run with a forefoot strike pattern ${ }^{24}$, probably demanding more work from the ankle extensor muscles (gastrocnemius and soleus $)^{55}$. It is possible that these differences between level running and graded running can explain the contradictory results obtained when compared to previous studies. Along these same lines, previous studies have reported that the neuromuscular capacity could be a relevant performance factor in uphill races ${ }^{2,24}$, a factor that could explain the relationship found between the calf circumference and the maximal and submaximal $\mathrm{VO}_{2}$ values. In this regard, it could be of interest to determine whether the calf circumference is also related to performance in mountain races over the different distances.

\section{Conclusions}

The results obtained in this study, compared to previously published studies show that the fat \% and the BMI of the short-distance trail runners appear to be lower than that of longer distance runners (>100 $\mathrm{km})$. With regard to the physiological characteristics, the results obtained herein for the values for $\mathrm{VO}_{2 \max } \mathrm{y} \mathrm{VO}_{2 \mathrm{VT} 1}$ and $\mathrm{VO}_{2 \mathrm{VT} 2}$ are similar to those obtained in other studies with short-distance trail runners. However, the $\mathrm{VO}_{2 \max }$ values of the runners taking part in this study, as well as those obtained in similar studies with short-distance runners, appear to be greater than those obtained for long-distance runners.

To the best of our knowledge, this is the first study to analyse the relationships between anthropometric characteristics and performance in a maximal continuous incremental incline test for short-distance amateur trail runners. It was observed that those study participants with a higher fat $\%$ and $\mathrm{BMI}$ achieved a lower Vel ${ }_{\mathrm{VT} 1}$, lower $\mathrm{t}_{\mathrm{VT} 1}$, lower $\mathrm{RER}_{\mathrm{VT2}}$ and lower $t_{\mathrm{VT}^{\prime}}$ indicating that those runners with a higher fat \% or BMI had a poorer submaximal performance with regard to the incremental incline test. Furthermore, significant positive correlations were observed between the between the calf circumference and $\mathrm{VO}_{2 \mathrm{VT} 1}, \mathrm{VO}_{2 \mathrm{VT} 2}$ and $\mathrm{VO}_{2 \text { max }}$. These results suggest that both fat $\%$ and $\mathrm{BMI}$ and the calf circumference could be determinant in performance in an incremental running incline test. Future studies, with a greater number of participants, could permit a multiple regression analysis and an in-depth study of the optimal combination of the different anthropometric variables in order to promote cardiovascular performance in standard laboratorybased incline incremental short-distance trail running tests. 


\section{Conflict of interest}

The authors have no conflict of interest at all.

\section{Bibliography}

1. 2019 Dossier de prensa. 2019. (Consultado 24/05/2020). Disponible en: https://itra. run/documents/Presse/2019/DP-ITRA-2019-ES.pdf.

2. Landart A, Cámara J, Urdampilleta A, Santos-Concejero J, Gómez J, Yanci J. Análisis de la fatiga neuromuscular y cardiovascular tras disputar una maratón de montaña. Rev Int Ciencias del Deport. 2020;59:43-56.

3. Björklund G, Swarén M, Born D-P, StögglT. Biomechanical adaptations and performance indicators in short trail running. Front Physiol. 2019;10:1-10.

4. Giandolini M, Vernillo G, Samozino P, et al. Fatigue associated with prolonged graded running. Eur J Appl Physiol. 2016;116:1859-73.

5. Easthope CS, Hausswirth C, Louis J, Lepers R, Vercruyssen F, Brisswalter J. Effects of a trail running competition on muscular performance and efficiency in well-trained young and master athletes. Eur J Appl Physiol. 2010;110:1107-16.

6. Matos S, Clemente FM, Brandão A, et al. Training load, aerobic capacity and their relationship with wellness status in recreational trail runners. Front Physiol. 2019;10:1-9.

7. Scheer V, Vieluf S, Cramer L, Jakobsmeyer R, Heitkamp H-C. Changes in running economy during a 65-km ultramarathon. Front Physiol. 2018:9:1-7.

8. Scheer V, Janssen TI, Vieluf S, Heitkamp HC. Predicting trail-running performance with laboratory exercise tests and field-based results. Int J Sports Physiol Perform. 2018; 14:130-3.

9. Belli T, Meireles CLDS, Costa M de O, Ackermann MA, Gobatto CA. Somatotype, body composition and performance in ultramarathon. Rev Bras Cineantropometria e Desempenho Hum. 2016;18:127-35.

10. Maciejczyk M, Wiecek M, Szymura J, Szyguła Z, Wiecha S, Cempla J. The influence of increased body fat or lean body mass on aerobic performance. PLoS One. 2014;9:e95797.

11. Maldonado S, Mujika I, Padilla S. Influence of body mass and height on the energy cost of running in highly trained middle- and long-distance runners. Int I Sports Med. 2002;23:268-72.

12. Hoffman MD, Lebus DK, Ganong AC, Casazza GA, Van Loan M. Body composition of 161-km ultramarathoners. Br J Nutr. 2010;31:106-9.

13. Rüst CA, Knechtle B, Knechtle P, Rosemann T. Comparison of training and anthropometric characteristics between recreational male half-marathoners and marathoners. Chin J Physiol. 2013;56:121-9.

14. Hoffman MD, Chen L, Krishnan E. Body mass index and its correlates in 1,212 ultramarathon runners: Baseline findings from the ULTRA study.J Phys Act Heal. 2014;11:1549-55.

15. Ehrström S, Tartaruga MP, Easthope CS, Brisswalter J, Morin JB, Vercruyssen F. Short trail running race: beyond the classic model for endurance running performance. Med Sci Sports Exerc. 2018;50:580-8.

16. Alvero-Cruz JR, Mathias VP, Garcia Romero J, Rosemann T, Nikolaidis PT, Knechtle B. Prediction of performance in a short trail running pace : the role of body composition. Front Physiol. 2019:10:1-7.

17. Fabre N, Balestreri F, Leonardi A, Schena F. Racing performance and incremental double poling test on treadmill in elite female cross-country skiers. J Strength Cond Res. 2010;24:401-7.

18. Gomez-Ezeiza J, Torres-Unda J, Tam N, Irazusta J, Granados C, Santos-Concejero J. Race walking gait and its influence on race walking economy in world-class race walkers. J Sports Sci. 2018:36:2235-41.

19. Millet GP, Dréano P, Bentley DJ. Physiological characteristics of elite short- and longdistance triathletes. Eur J App/ Physiol. 2003;88:427-30

20. Morgan PT, Black MI, Bailey SJ, Jones AM, Vanhatalo A. Road cycle TT performance: Relationship to the power-duration model and association with FTP. J Sports Sci. 2018;37:902-10

21. Balducci P, Clémençon M, Morel B, Quiniou G, Saboul D, Hautier CA. Comparison of level and graded treadmill tests to evaluate endurance mountain runners. J Sport Sci Med. 2016;15:239-46.

22. Fornasiero A, Savoldelli A, Fruet D, Boccia G, Pellegrini B, Schena F. Physiological intensity profile, exercise load and performance predictors of a $65-\mathrm{km}$ mountain ultra-marathon. J Sports Sci. 2017;36:1287-95

23. Scheer V, Ramme K, Reinsberger C, Heitkamp HC. VO ${ }_{2 \max }$ testing in trail runners: is there a specific exercise test protocol? Int J Sports Med. 2018;39:456-61.
24. Vernillo G, Giandolini M, Edwards WB, et al. Biomechanics and physiology of uphill and downhill running. Sport Med. 2016;47:615-29.

25. Balducci P, Clemençon M, Morel B, Quiniou G, Saboul D, Hautier CA. Comparison of level and graded treadmill tests to evaluate endurance mountain runners. J Sport SCi Med. 2016;15:239-46.

26. Russell AM, Benton D, Kingsley M. Compression garments, muscle contractile function and economy in trail runners. Int J Sports Physiol Perform. 2016;12:62-8.

27. Scheer $V$, Vieluf S, Janssen TI, Heitkamp H. Predicting competition performance in short trail running races with lactate thresholds. J Hum Kinet. 2019;69:239-47.

28. Tan PL, Tan FH, Bosch AN. Assessment of differences in the anthropometric, physiological and training characteristics of finishers and non-finishers in a tropical 161-km ultra-marathon. Int J Exerc Sci. 2017;10:465-78.

29. Hetland ML, Haarbo J, Christiansen C. Regional body composition determined by dual-energy x-ray absorptiometry. Relation to training, sex hormones, and serum lipids in male long-distance runners. Scand J Med Sci Sports. 1998;8:102-8.

30. McLaughlin JE, Howley ET, Bassett DR, Thompson DL, Fitzhugh EC. Test of the classic model for predicting endurance running performance. Med Sci Sports Exerc. 2010;42:991-7.

31. Wüthrich TU, Marty J, Kerherve H, Millet GY, Verges S, Spengler CM. Aspects of respiratory muscle fatigue in a mountain ultramarathon race. Med Sci Sports Exerc. 2015; 47:519-27

32. Mooses M, Jürimãe J, Mãestu J, Mooses K, Purge P, Jürimãe T. Running economy and body composition between competitive and recreational level distance runners. Acto Physiol Hung. 2013;100:340-6.

33. Jürimäe J, Tillmann $V$, Purge $P$, Jürimäe T. Body composition, maximal aerobic performance and inflammatory biomarkers in endurance-trained athletes. Clin Physiol Funct Imaging. 2017;37:288-92.

34. Bergh U, Sjödin B, Fosberg A, Svedenhag J. The relationship between body mass and oxygen uptake during running in humans. Med Sci Sports Exerc. 1991;23:205-11.

35. Akça F. Prediction of rowing ergometer performance from functional anaerobic power, strength and anthropometric components. J Hum Kinet. 2014;41:133-42

36. Mooses M, Jürimäe J, Mäestu J, Purge P, Mooses K, Jürimäe T. Anthropometric and physiological determinants of running performance in middle-and long-distance runners. Kinesiology. 2013;45:154-62.

37. Hoffman MD. Anthropometric characteristics of ultramarathoners. Int J Sports Med 2008:29:808-11.

38. Marfell-Jones M, Olds T, Stewart AD, Carter L. International standards for anthropometric assessment. Potchefsroom, South Africa: The International Society for The Advancement of Kim Anthropometric; 2006.

39. Yuhasz M. Equations for measuring body fat using skinfold measures. Phys Fit Man 1974

40. Heath BH, Carter JEL. A modified somatotype method. Am J Phys Anthropol. 1967:27:5774.

41. Wasseran K, Whipp BJ, Koyal SN, Beaver WL. Anaerobic threshold and respiratory gas exchange during exercise. J Appl Physiol. 1973;35:236-43.

42. Koike A, Wasserman K, Mckenzie DK, Zanconato S, Weller-ravell D. Evidence that diffusion limitation determines oxygen uptake kinetics during exercise in humans. Clin Invest. 1990;86:1698-06.

43. Wasserman K, Beaver WL, Whipp BJ. Gas exchange theory and the lactic acidosis (anaerobic) threshold. In: Circulation. 1990;81:14-30.

44. Bentley DJ,VleckVE, Millet GP.The isocapnic buffering phase and mechanical efficiency: relationship to cycle time trial performance of short and long duration. Can J Appl Physiol. 2005;30:46-60.

45. Chicharro JL, Hoyos J, Lucia A. Effects of endurance training on the isocapnic buffering and hypocapnic hyperventilation phases in professional cyclists. Br J Sports Med. 2000;34:450-5.

46. Pallarés JG, Morán-Navarro R, Ortega JF, Fernández-Elías VE, Mora-Rodriguez R. Validity and reliability of ventilatory and blood lactate thresholds in well-trained cyclists. PLOS One. 2016;11:1-16

47. Hopkins WG, Marshall SW, Batterham AM, Hanin J. Progressive statistics for studies in sports medicine and exercise science. Med Sci Sports Exerc. 2009;41:3-12.

48. Knechtle B. Relationship of anthropometric and training characteristics with race performance in endurance and ultra-endurance athletes. Asian J Sports Med. 2014:5:73-90.

49. Rivas LG, Mielgo-Ayuso J, Norte-Navarro A, Cejuela R, Cabañas MD, Martínez-Sanz JM Composición corporal y somatotipo en triatletas universitarios. Nutr Hosp. 2015:32:799-07.

50. Tanda G, Knechtle B. Marathon performance in relation to body fat percentage and training indices in recreational male runners. J Sports Med. 2013:4:141-9. 
51. Lucia A, Esteve-Lanao J, Oliván J, et al. Physiological characteristics of the best Eritrean runners - exceptional running economy. Appl Physio/ Nutr Metab. 2006;3:530-40.

52. Knechtle B, Knechtle P, Rüst CA, Rosemann T. Leg skinfold thicknesses and race performance in male 24-hour ultra-marathoners. Baylor Univ Med Cent Proc. 2011:24:110-4.

53. Arrese AL, Ostáriz ES. Skinfold thicknesses associated with distance running performance in highly trained runners. J Sports Sci. 2006;24:69-76.

54. Lazzer S, Salvadego D, Taboga P, Rejc E, Giovanelli N, Di Prampero PE. Effects of the Etna uphill ultramarathon on energy cost and mechanics of running. Int J Sports Physiol Perform. 2015;10:238-47
55. Willis SJ, Gellaerts J, Mariani B, Basset P, Borrani F, Millet GP. Level versus uphill economy and mechanical responses in elite ultra-trail runners. Int J Sports Physiol Perform. 2019;14:1001-5

56. Kong PW, De Heer H. Anthropometric, gait and strength characteristics of Kenyan distance runners. J Sport Sci Med. 2008;7:499-04.

57. Russell AM, Benton D, Kingsley M. Anthropometrics and body composition in East African runners: potential impact on performance. Int J Sports Physiol Perform. 2016;12:422-30

58. Saunders PU, Pyne DB, Telford RD, Hawley JA. Factors affecting running economy in trained distance runners. Sport Med. 2004;34:465-85. 